\title{
EMERGENCY INVESTIGATION OF EXTREMELY LARGE SINKHOLES, MAOHE, GUANGXI, CHINA
}

\author{
Mingtang Lei, Xiaozhen Jiang, Zhende Guan \\ Institute of Karst Geology, CAGS, Guilin, China, mingtanglei@hotmail.com \\ Yongli Gao \\ Department of Geological Sciences, Center for Water Research, University of Texas at San Antonio, TX 78249, USA, \\ yongli.gao@utsa.edu
}

\begin{abstract}
A series of sinkholes collapsed at Maohe village, Liuzhou, Guangxi, China. The collapsing event formed 41 sinkholes, 11 donut-shape subsidence areas and 68 fractures in May of 2012. Many ground failures and fractures formed and an area of $40000 \mathrm{~m}^{2}$ was impacted by the collapsing event. The collapsing event was caused by large scale soil piping and soil void collapses. Preliminary investigations revealed that drastic fluctuations of karst water level caused this collapsing event. Heavy precipitation along with bedrock roof collapse of underground streams may trigger a "water hammer" effect in the karst conduits. The "water hammer" effect caused severe soil damage and subsequent collapses in Maohe Village. Soil disturbance may cause a change in hydraulic gradient, causing water level fluctuations that eventually resulted in sinkhole collapses. By monitoring pressure changes of karst water, turbidity of groundwater, locating soil voids and soil disturbances using ground penetrating radar (GPR), it is possible to predict future sinkhole collapses.
\end{abstract}

\section{Introduction}

On May 10 2012, a series of sinkholes collapsed at Maohe village, Liuzhou, Guangxi, China. The collapsing event formed 15 sinkholes ranging from 4 to $30 \mathrm{~m}$ in diameter and 2 to $10 \mathrm{~m}$ in depth within one hour after 10:20 am. By May 15, 41 sinkholes collapsed. Eleven donut-shape subsidence areas and 68 fractures formed in the area. Many ground failures occurred and an area of $40,000 \mathrm{~m}^{2}$ was impacted by the collapsing event and an area of $10,000 \mathrm{~m}^{2}$ suffered severe damage. Because the collapsing events occurred in areas with high population density, an initial investigation revealed severe damage of 143 residential houses (69 collapsed), 8 factory buildings, and 3 buildings currently under construction. Two elementary schools and one middle school were impacted and 1830 people were relocated. Direct loss of property damage is estimated to be at least 20 million CNY ( $>3$ million US dollars). This paper discusses the geologic background of the study, mechanism of sinkhole collapses, and prevention and treatment of sinkhole hazards in the study area.

\section{Geologic Setting}

Maohe village is located in a highly active karst area and many karst features such as sinkholes, springs, karst windows, caves, and conduit systems are widely distributed in this area. The area is a typical karst plain with isolated karst towers. The altitude of the ground surface is about $92.53-94.16 \mathrm{~m}$. The unconsolidated sediments above bedrock are Quaternary alluvium and colluvium deposits with thicknesses ranging between $3.70 \mathrm{~m}$ and $17.10 \mathrm{~m}$. The Quaternary deposits are comprised of colluvium clay, silty clay, rounded gravels, and red clay. The bedrock is thick light-gray dolostone belonging to the middle Carboniferous Dapu formation $\left(\mathrm{C}_{2 \mathrm{~d}}\right)$. The dolostone is brittle with many fractures and joints. The upper layer of bedrock dips to the east with dipping angles less than 5 degree. The altitude of the top of the bedrock is $74.30-87.76 \mathrm{~m}$ and depth to bedrock is $4.70-38.50 \mathrm{~m}$ (Figure 1).

The study area is a covered karst area. Bedrock is highly fractured due to faulting and tectonic movements. Karstification is highly active along joints and fault zones, which causes more relief of bedrock topography. Voids and caves are commonly encountered during drilling processes. Thirty three out of $71(46.5 \%)$ drilling cores showed that caves exist within bedrock. Sixty six caves are detected from drilling with heights ranging from 0.20 to $14.60 \mathrm{~m}$. The number of caves decreases drastically with depth and almost all caves are distributed within the uppermost $20 \mathrm{~m}$ of bedrock. Most caves were filled with clay and dolostone debris, especially caves close to the top of the bedrock. Fifty two caves are filled and 14 caves are empty. The filling rate is $78.8 \%$ (Figure 2). 

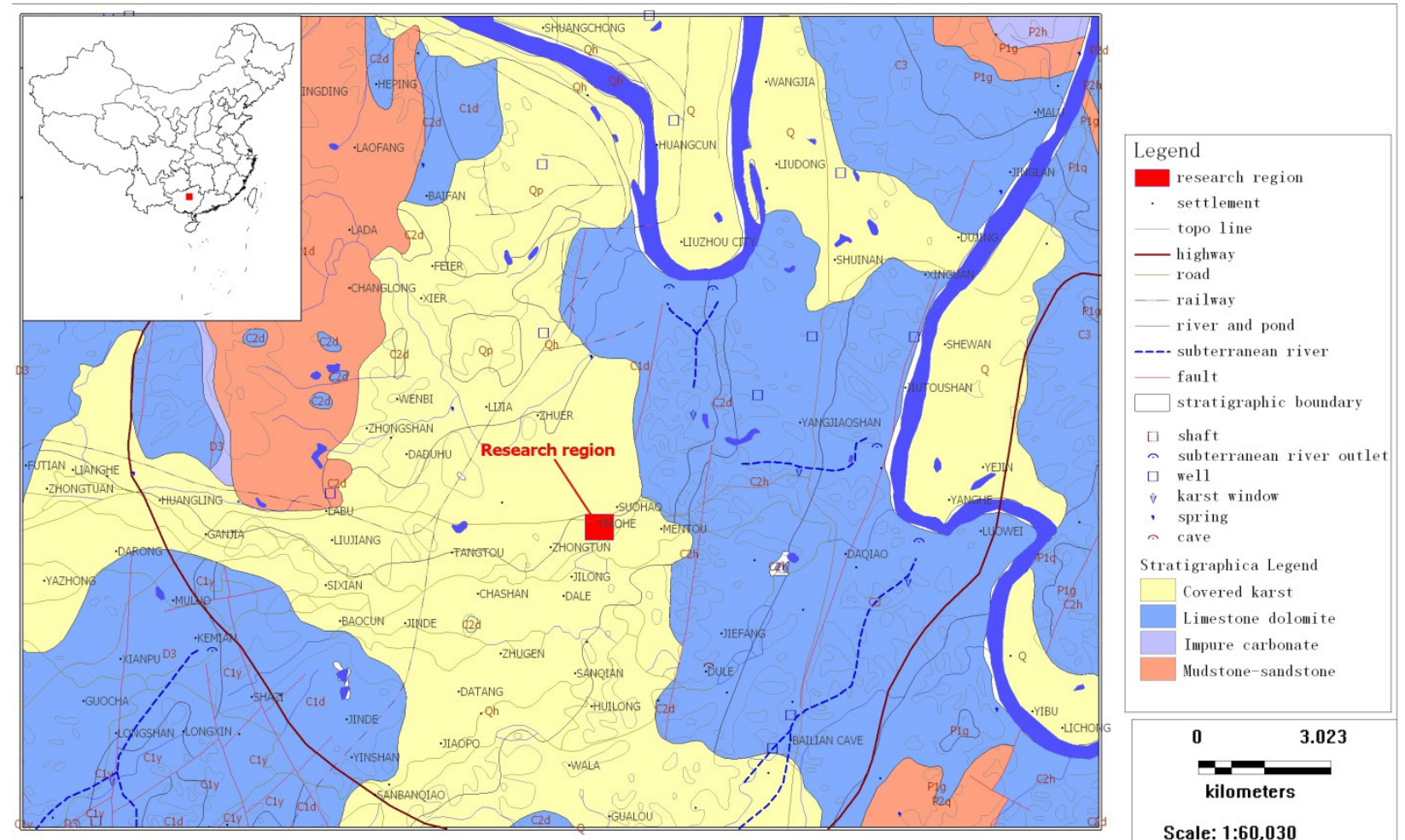

Figure 1. Geologic Map of the study area.

Groundwater resources include water in porous Quaternary deposits and karst water within bedrock matrix, fracture, and conduits. A limited amount of Quaternary water is mainly stored within a silty clay aquifer with a depth of $1-7 \mathrm{~m}$ and water level ranges between 1 and $3 \mathrm{~m}$. A significant amount of karst water exists in fractures and conduits of the dolostone bedrock. The depth of the water table ranges between 1.60 and $5.95 \mathrm{~m}$ and the altitude of the water level is $88.25-90.02 \mathrm{~m}$.

\section{Water Pumping and Sinkhole Distribution}

There is only one deep well that pumps in this area. The well was drilled in 1990 and is located in the northeastern corner of the study area. The well depth is $95 \mathrm{~m}$ and the average pumping rate is approximately $150 \mathrm{~m}^{3} / \mathrm{day}$. There are many hand-dug wells in Shangmuzhao section used for laundry. Most domestic water usage is from city water systems. No heavy pumping of groundwater ever occurred and a cone of depression does not exist in the study area.

Forty-one sinkholes, 11 donut-shaped subsidence areas, and 68 fractures formed in the area (Figure $3 \& 4$ ). Most sinkholes are circular or elliptical in shape on the surface and cone shape below surface. The largest sinkhole is no. 11 with an irregular shape on the surface and a long axis of $70.0 \mathrm{~m}$, short axis of $12.0-38.0 \mathrm{~m}$, and a depth of 4.0 $\mathrm{m}$. The smallest sinkhole is no. 30 with a diameter of 1.2 $\mathrm{m}$ and a depth of $5.0 \mathrm{~m}$. Groundwater flowed out to the surface when this sinkhole collapsed and all of the water disappeared through the bottom of the sinkhole after a few minutes. Subsidence area no. 2 is the largest with an irregular shape on the surface and a length of $33.0-36.0$

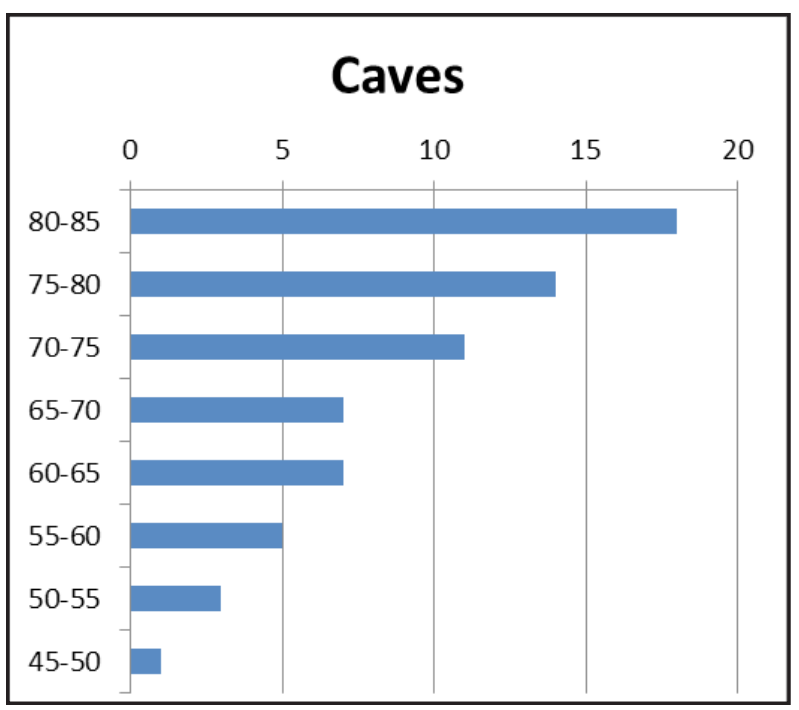

Figure 2. Subsurface cave distribution based on drilling records. Vertical axis indicates elevation $(\mathrm{m})$ above sea level. 


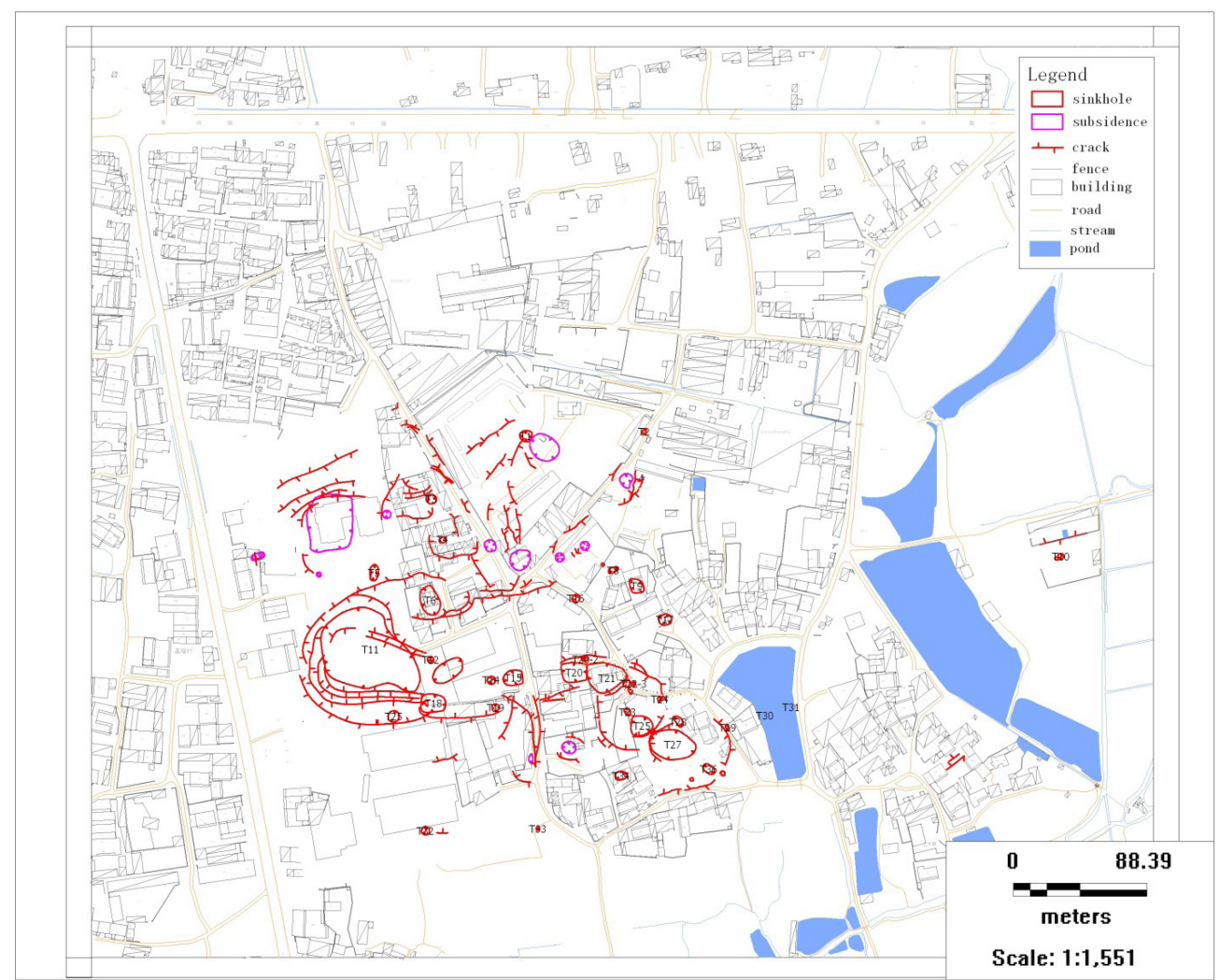

Figure 3. Sinkhole distribution in the study area.
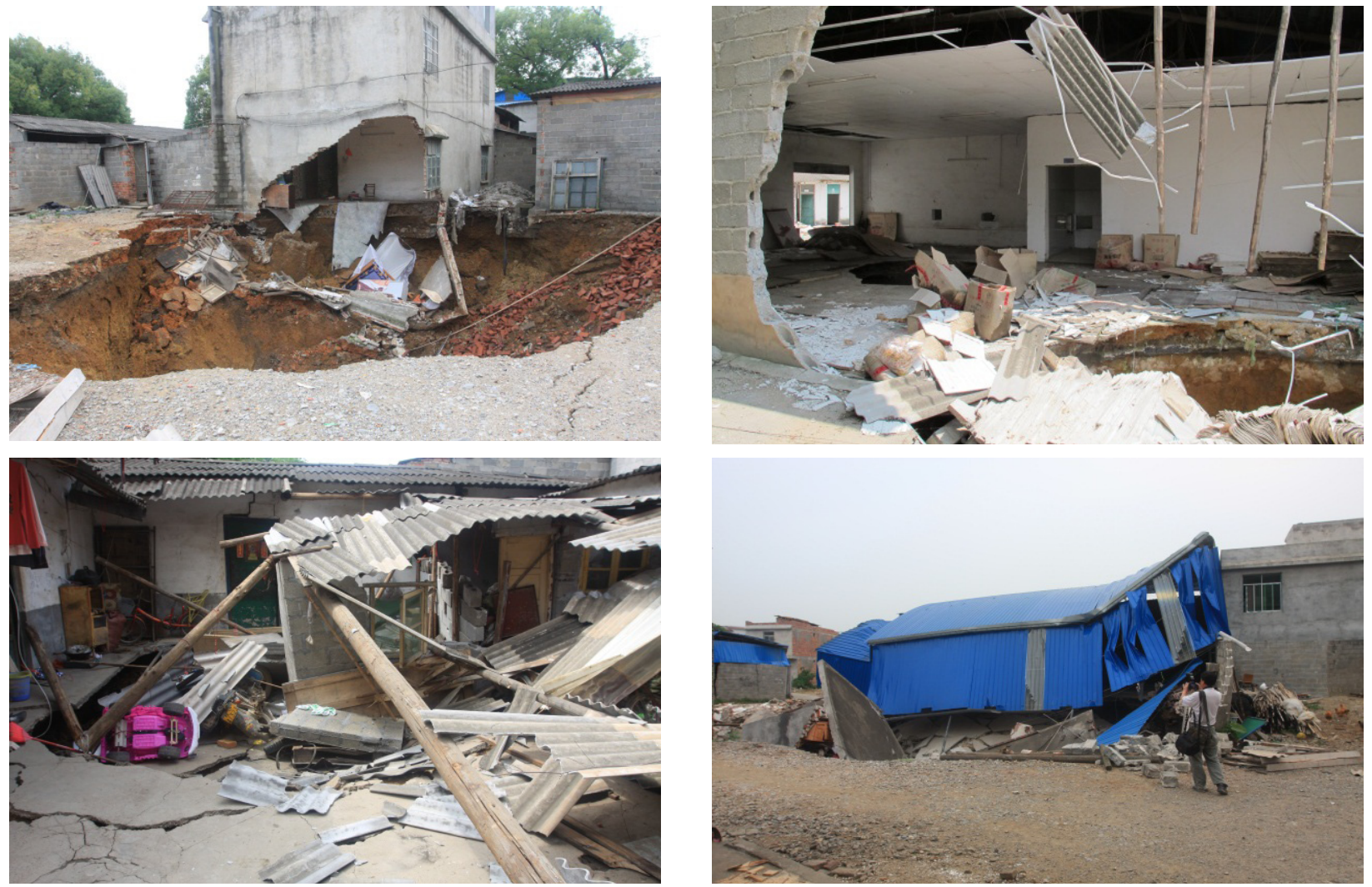

Figure 4. Typical sinkhole collapses in the study area. 
$\mathrm{m}$, width of $23.0-26.0 \mathrm{~m}$, and a depth of $1.0 \mathrm{~m}$ at the center of the subsidence. Four fractures formed around this subsidence area, which caused building no. 4 to be tilted to the north.

Most sinkholes formed at the Shangmuzhao section of Maohe village and the overall distribution is along zones of NW - SE orientation. The water was turbid in a handdug well and many air bubbles were released from the well on May 10. Total suspend solids were about $10 \%$ from pumped groundwater. By May 14, the well had already collapsed (Figure 5).

\section{Results and Discussion}

Collapsing events were caused by soil piping and deformation due to highly fluctuating hydraulic conditions within the karst water system. Karst features such as cave streams, large karst springs, karst windows, caves, and blue holes exist in the study area.

On-site investigations revealed that initial collapses occurred during heavy rainfall. Rapid water level rise caused cave roof collapse, which may trigger a "water hammer" effect in the karst conduit system. The "water hammer" effect can release a pressure surge to the karst conduit system, causing severe soil damage and subsequent collapses (Lei et al., 2010; Gao et al., 2013). Soil disturbance would change the hydraulic gradient, which can cause water level fluctuations and eventually result in new sinkholes. Red clay near the bedrock could be disturbed with seepage deformations which may trigger sinkhole collapses.

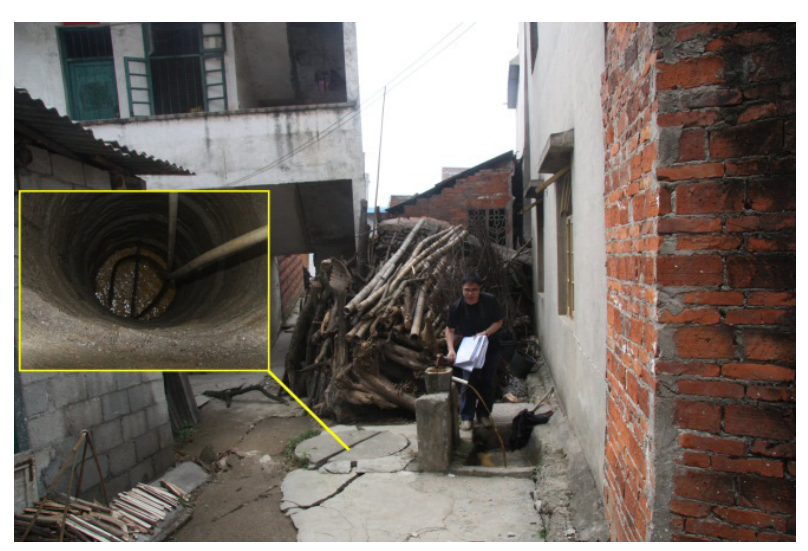

The karst water level is recovering to normal conditions after the collapsing event. It is unlikely for large scale collapsing events to occur in the near future because of non-fluctuating water levels. However, small scale sinkholes and subsidence may continue due to the disturbance of sediments. Large scale sinkhole collapses may occur again during monsoon seasons. It may take several years to stabilize the soil to normal hydraulic conditions.

\section{Conclusions}

Rapid water level rise after a storm event caused a series of collapsing events in Maohe village. Several collapsing events were caused by extreme weather conditions (Gao et al., 2013). Further studies of the relationship between an extreme weather event and sinkhole collapses need to be conducted to prevent such large scale collapsing events in the future.

Compared to limestone settings, the karstification of dolostone was traditionally thought to be relatively weak and the study area has long been listed as a low risk sinkhole area. This study demonstrates that severe damage can be caused by large scale sinkhole collapses in a dolostone karst area.

By monitoring pressure changes of karst water and turbidity of groundwater and locating soil voids and soil disturbances using ground penetrating radar (GPR), it is possible to predict future sinkhole collapses (Jiang et al., 2008; Jiang et al., 2013; Lei et al., 2008; Lei et al., 2010). These approaches are being used to prevent future sinkhole collapses and to reduce the damage caused by the collapsing event.

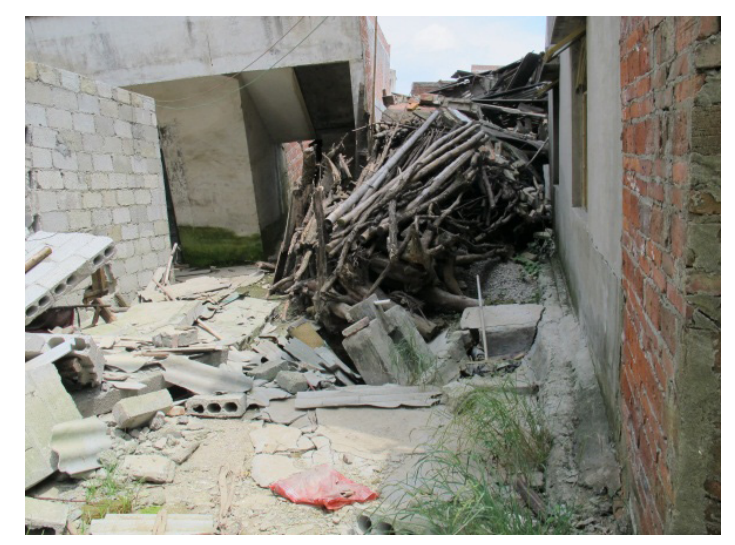

Figure 5. Hand-dug well with high turbidity and air bubbles (L) collapsed on May 14, 2012 (R). 


\section{References}

Gao Y, Luo W, Jiang X, Lei M, Dai J. 2013. Investigations of Large Scale Sinkhole Collapses, Laibin, Guangxi, China (this volume).

Jiang X, Lei M, Gao Y, Meng Y, Sang X. 2008. Monitoring soil void formation along highway subgrade using Time Domain Reflectometry (TDR), a pilot study at Guilin-Yangshuo highway, Guangxi, China. In: Yuhr L, Alexander E, Beck B, editors. Proceedings of the Eleventh Multidisciplinary Conference on Sinkholes and the Engineering and Environmental Impacts of Karst. ASCE Geotechnical Special Publication no. 183. p.213-222.

Jiang X, Lei M, Gao Y, Guan Z. 2013. Characterization of Karst Collapse Hazard Based on Groundwater Fluctuations in Qingyun village, Guigang, Guangxi, China (this volume).

Lei M, Gao Y, Li Y, Meng Y, Yu L, Gan F. 2008. Detection and treatment of sinkholes and subsurface voids along Guilin - Yangshuo highway, Guangxi, China. In: Yuhr L, Alexander E, Beck B, editors. Proceedings of the Eleventh Multidisciplinary Conference on Sinkholes and the Engineering and Environmental Impacts of Karsts. ASCE Geotechnical Special Publication no. 183. p.632-639.

Lei M, Jiang X, Li Y, Meng Y, Dai J, Gao Y. 2010. Predicting sinkhole collapse by long-term monitoring of karst water pressure in Zhemu, China. Geologically Active: Proceedings of the 11th IAEG Congress, Auckland, New Zealand. p. 355-362. 
